\title{
Newly Emerged Online Educational Framework in Nursing Major during the Pandemic of COVID-19
}

\author{
Omar M. Khraisat ${ }^{1}$, Ahmad M. Al-Bashaireh ${ }^{2}$, Mohammad O. Khraisat ${ }^{3}$, \\ Fatima H. Khraisat, HD ${ }^{4}$, Eman Nazly, PhD, RN ${ }^{5}$, Mohannad A. Aldiqs, MSN, RN ${ }^{6}$ \\ ${ }^{1}$ Assistant Professor, Head of Department, Al-Ahliyya Amman University (AAU)/Faculty of Nursing, Jordan, \\ ${ }^{2}$ Assistant Professor, Vice Dean for Academic Affairs, Al-Ahliyya Amman University (AAU)/Faculty of Nursing, \\ Jordan, ${ }^{3}$ Medical Doctor, Cairo University, Kasr Alainy Faculty of Medicine, Egypt, ${ }^{4}$ Primary School Chairman, \\ Jordanian Ministry of Education, Jordan, ${ }^{5}$ Associate Professor, Vice Dean for Deanship of Scientific Research, Al- \\ Ahliyya Amman University (AAU), Jordan, ${ }^{6}$ Mohannad A. Aldiqs MSN, RN, CNS, Lecturer, Mental Health Nursing, \\ Al-Ahliyya Amman University (AAU)/Faculty of Nursing, Jordan
}

\begin{abstract}
The pandemic of COVID-19 has globally interrupted the education systems. Many countries including Jordan forcefully moved to online education. This study is designed to build an innovative Framework to overcome the concerns and challenges of online clinical teaching.

A cyclical module of the Online Clinical Training Pathway (OCTP) was created to provide an opportunity for students to document their learning, in the form of a reflection guide. Each module aims to attain the intended learning outcomes through a set of four integrated learning activities. OCTP success was assessed by regular evaluation parallel with semi-structured interview targeted faculty members and students across courses and student levels. The results emerged a new framework of the teaching and learning of synchronous distance learning among participants. Technical limitations were also observed with regards to internet-connection speed and reliability. Quality indicators of the synchronous and asynchronous online environment were issues that need to be addressed. Creating opportunities to enhance online engagement through the use of new framework methodology provides a promising direction to bring experiential education into the online context.
\end{abstract}

Keywords: Clinical, COVID-19, Education, Framework, Nursing, Online.

\section{Introduction}

The pandemic ofCOVID-19 has globally interrupted the social, economic, and education systems. Many countries around the world suspended their schools, academic institutions, and gathering places to minimize its contagiousness and lethality.

\section{Corresponding Author:}

Mr. Mohannad A. Aldiqs

Jordan-P.O. Box 311, Amman 19328, Al-Ahliyya

Amman University (AAU)/Faculty of Nursing

Tel: + 00962 53500211, Ext (2536),

Fax +0096265335169

e-mail: m.aldiqs@ammanu.edu.jo, m-aldigs@hotmail.com
Our institution, a private university, offers a BScs nursing program, and as a consequence of the government orders directed toward the control of the spread of new COVID-19 infection in Jordan. University moved to a dual system of synchronous (Microsoft Team) and asynchronous distance learning (V class/Moodle) in March 2020. There are particular considerations for clinical courses in nursing. Nursing faculty members were under pressure and they need to be innovative to overcome concerns and challenges while teaching clinical courses since online education replaced the traditional face-to-face on-campus classes. Other concerns were challenging, as the emphasis on student interactions, continuity of quality of education, achieving the learning outcomes, and aiming to attain highly caliper competencies following Benner's $\operatorname{model}^{(1)}$. 
Nursing faculty adopted Benner's model (2001) that describes five levels of proficiency in nursing to obtain the specialized competencies for each clinical course.

Thus, this study aimed to build an innovative Framework to overcome the concerns and challenges of online clinical teaching.

\section{Challenges and Resolution: Learned Lessons:}

Ensure the Lecturer Sees Participants' Faces along with the Lecture Slides: It is always helpful for lecturers to see students' faces to recognize students' reactions. Microsoft Teams can display up to 40 participants on a screen and allows users to use dual screens ${ }^{(2,3)}$. Unfortunately, the number of students you can display depends on your (Personal Computer) PC's specification. The instructor PC's CPU should be Intel i7 or equivalent to be able to show 49 participants on display (4). If the computer has Intel Quad-Core i3, so it could only display 15 on a window, and when there are a larger number of participants, the instructor needs to scroll the window to watch all students, which is not convenient $(4,5)$. So, instructors need to use two sets of PC and external monitors to see all participants. Additionally, the quality of the internet used by the Instructor may limit the uses of options within the Microsoft Team.

The Quality Standards of Case Sceneries: The online-training methodology is a method that tries to rebuild real-world characteristics and to enhance learners' clinical judgment, by using a problemsolving approach integrated into interactive learning scenarios $^{(3,4)}$. These scenarios provide students with practical experience and immediate feedback through debriefing and guided reflection ${ }^{(7)}$.

Faculty of Nursing adopted a set of quality standards when the case sceneries designed as follows: (a) identify patient and other problems apparent or expected in the case, (b) suggest alternative problems that might be possible if more information were available, (c) identify the information needed, (d) identify relevant and irrelevant information in the case, (e) interpret the information to enable a response, (f) propose different approaches that might be used, weigh approaches against the evidence, select the best approaches for the case situation, and provide a rationale for those approaches, (g) Identify gaps in the literature and evidence as related to the case, and (h) evaluate the effectiveness of interventions, and plan alternative interventions based on analysis of the case.
Student-Instructor Interactions: Due to such imminent challenge with online courses, interaction is one of the major factors that were also extensively investigated in several studies ${ }^{(7,8,9)}$. Determinants of student interaction in online learning were a lot. Learners' style, instructor teaching style, course content, course design and length, instructional style, class size, and support system are examples of such determinants ${ }^{(7,8,9)}$.

The online teaching environment creates some obstacles for student-instructor interactions during the sessions. Several actions need to be considered by the Instructor. Instructors normally need to ask students to mute their microphones during the session, as microphones can catch a background noise, which makes the instructor's voices less audible. Even if the Instructor displays all students' faces, it is still challenging for a lecturer to visually notice signs that students want to say something. Instructors need to more systematically (rather than naturally) organize interactions.

To enhance students' readiness and interaction in a weekly manner proceeding of the online session, the standardized videos, competency checklists, and structured case scenarios were uploaded on a synchronize (MOODLE/V class) system.

Further, on daily basis, the Clinical Training Portfolio was used by the instructor. Portfolios are valuable for clinical evaluation because students provide evidence in their portfolios to confirm their clinical competencies and document new learning and skills acquired in a course. The focus will be on inter-professional communication, collaboration professionalism, and teamwork by applying meaningful, and realistic scenarios ${ }^{(9)}$ followed by a guided reflection that is a helpful tool in health care, to develop professional practice and improve the quality of care $^{(3,10)}$.

Evaluation for Students' Interaction: In followup for debriefings of student-instructor interactions, the training provided to learners with feedback about their professional manner, attitude, and interpersonal skills, thus promoting standardized, rather than personal learning; this feedback is immediate and from the critical point of the adopted course portfolio.

The evaluation was conducted in three steps. The first step aimed to assess the current status of each competency for students based on the course portfolio. An evaluation was conducted every week. Various method focusing on the critical and/or core points were 
used such as the folded and unfolded case scenario, selfexam module, short quizzes, and students' presentation. The second step aimed to explore the opportunities for improvement; the faculty members were conducted a weekly basis meeting to do a gap analysis to each course. The analysis was done by discussing the achievement report provided in the form of reflection which includes the target and desired level of competencies based on Benner's adopted model.

In the third step, the evaluation aimed to follow up on the implementation of the action plan using an objective structured clinical examination (OSCE) and a final written exam. OSCE and the final written exam cover all educational materials uploaded in the MOODLE and matched with the Nursing Student Clinical Training Portfolio and parallel with learning outcomes for each clinical course.

\section{Method}

The study was guided by Benner's model. Online Clinical Training Pathway (OCTP) was created to provide an opportunity for students to document, in the form of a reflection guide. Using a semi-structured interview, purposive sampling of faculty members (focus group) $(\mathrm{n}=4)$ and students $(\mathrm{n}=6)$ from different courses and levels were recruited to evaluate barriers and facilitators of OCTP utilization.

The interviewer (moderator) guided the discussion according to a written set of questions or topics to be covered, as in a semi-structured interview. Focus group sessions are carefully planned discussions that take advantage of group dynamics for efficiently accessing rich information in an efficient manner. Typically, the people selected for a group (usually through purposive or snowball sampling) are a fairly homogeneous group, to promote a comfortable group dynamic. The setting for the focus group sessions selected carefully and, ideally, should be a neutral one.

Analysis: Use quantitative method as adjuncts to qualitative analysis was used similar to Kidd et al., (11). Filling gaps of OCTP evaluation and return demonstration end by implementing a New framework for clinical course distance training.

Ethical Considerations: Written IRB approval was obtained as an expedited review from the Scientific Research Committee of Nursing Faculty at Al-Ahliyya Amman University (AAU).

\section{Results}

Newly Emerged Online Framework: The huge challenges in online teaching for clinical courses were to tell students exactly what they should achieve and to continuously monitor their progression. The student is required to learn predetermined sets of intended learning outcomes for each course supervised by Faculty members.

$\mathrm{He} / \mathrm{she}$ worked intensively and closely with the administrative support system to make this framework evident and ready for implementation. First, there is an agreement to run the clinical training in three phases: Phase- 1 preliminary phase (pre-training phase) refers to the activities and preparatory work made before the actual conduct of training. In this phase, actual preparations are made for launching the program. It involves the following activities: assessment of the needs of training design, and development of the training courses according to intended learning outcomes.

Phase -2 will follow the framework that was created and named as Online Clinical Training Pathway (OCTP) (Figure 1). Figure 1 describes the four consequent steps during the OCTP. Before the launching of OCTP and going live a crash session was conducted to all faculty members to explain the OCTP steps, integrate OCTP effectively within in a dual system of synchronized and a synchronized online training, and to obtain feedback of online training via a structured weekly performance report submitted by the instructors to the coordinator of clinical training.

In phase- 2 of OCTP, students will be assigned to direct assignments depending on their level of learning and the nature of the course (e.g. standardized video, case scenarios, short essay, questions, log paper, self-exam module, and critical point care, etc.). All assignments were submitted through a synchronized online learning platform (V-class/Moodle). Following the assignments submission, all graded assignments will be discussed in an interactive online session conducted via synchronized distance learning (Microsoft Team). The online session via Microsoft Team provides students a chance to interact with their instructors and other students and help faculty members to explore the clinical reasoning and judgment of their students.

Additionally, students need to go a long standardized video, and competency-based check-off based on the National Council Licensure Examination (NCLEX) 
standards. Students are required to be mastered certain psychomotor skills in a real clinical setting. So, a structured of folded and unfolded case scenarios were built and match with clinical intended learning outcomes for each course and compatible with the Nursing Student Clinical Training Portfolio to achieve this goal. These blended method provided to students in touch with the clinical area will enhance their critical thinking, reasoning, and clinical judgment once since they are way from the clinical area due to the constraints of lockdown and quarantine associated with the pandemic state of COVID-19.

In phase 2 evaluation is evident and continuously monitored, it is a process to determine the relevance, effectiveness, and impact of activities in light of their objectives. In this phase, four criteria were included: reaction, learning, behavior, and results. OCTP program is continuously assessed and the gap noticed in this training will be followed by remedial actions after the commencement of education on campus. Phase 3 and phase 4 were proposed based on the continuous evaluation method during phase 2 . In phase 3 and phase 4 , a 2 weeks intensive training in a simulation lab followed by a final written exam and objective structured clinical examination (OSCE) are an example of future proposed remedies. The integration of all online training phases starting from preliminary to OCTP use and evaluation process was ended by the emerging Khraisat and Al-Bashaireh Distance Training Model (KADTM) as showed in Figure 1.

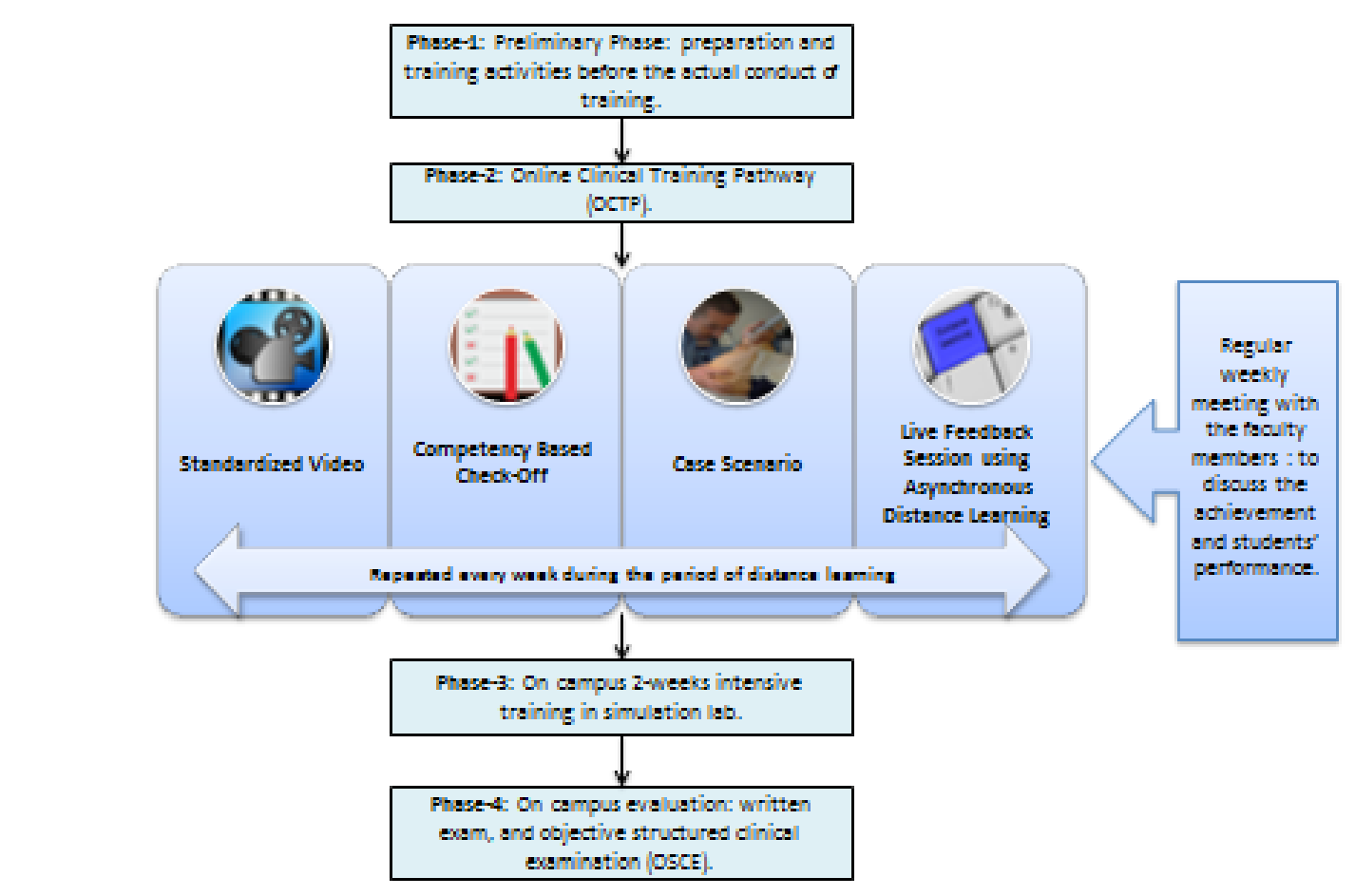

Figure 1: New Framework for Clinical Courses: Distance Learning Followed by Proposed On-Campus Training and Evaluation [Khraisat and Alseshaireh Distance Training Model [KADTM).

\section{Discussion}

Evaluation of Implementation of New Framework: As part of the evaluation of the implementation of the new framework, a semistructured interview was used among a focus group of faculty members to assess barriers and facilitators of effective utilization of Synchronous Distance Learning (Microsoft Team) and Asynchronous Distance Learning (V-class/Moodle).
Data were collected on Tuesday (17/3/2020) between 08:00 and 11:00 pm, after 3 days of using Microsoft Team. Also, another (6) students from different courses and levels were involved by using a semi-structured interview to evaluate their responses to the implementation of online education during the pandemic crisis.

The faculty members reported that online teaching is a new experience; they learned a new strategy of 
teaching synchronous distance learning. It may be used in the future as a supportive tool for the classical session. They reported that student culture needs time to be improved regarding the use and application of ethical standards when they are online. Additionally, they reported that evaluation was difficult for clinical courses since a large number of students.

Further, students reported that they were able to catch the required information from instructors in theory courses. However, they think the challenge wherewith the clinical courses. All students think they able to achieve $70-100 \%$ of learning outcomes for the course of theory; however, they think they may able to achieve 30$40 \%$ of learning outcomes in clinical courses. Similarly, 5 of 6 students said it was a great experience," I learned a new strategy of the teaching of synchronous distance learning". The majority of the students (4 out of 6 ) reported they were gotten a huge material even more than before (classroom) and they spend more time reading and preparation. They were highly committed to attend the online class was reported by 5 out of 6 students.

Technical problems reported in (e.g. accessing, hearing Instructors' voices, internet disconnection, shared folder appearance, Instructor control for the session) with Microsoft Team and Moodle (50\%). The mainstream of the students expresses a fear concerning the evaluation process. 4 out of 6 students ask for more flexibility from their Instructors concerning the deadlines, quizzes, attendance, and feedback.

Hence, the first few days up to the first week most of the issues were related technologies such as access, use, connectivity, voice, noise, and control while using Moodle or Microsoft Team. However, in the second week, these complaints vanished, students become more focused on the material, reading, Instructor feedbacks, and the anxiety toward the midterm exam.

\section{Conclusions}

Both faculty members and students reported they “ learned a new strategy of the teaching and learning of synchronous distance learning". Distance Learning is an educational occasion that helps students to understand the content better and improves their engagement in learning.

Creating opportunities to enhance online engagement through the use of simulation provides a promising direction to bring experiential education into the online context; in light of the COVID-19 outbreak and preparation for potential future outbreaks, the provision of such opportunities becomes critical in higher education contexts. Although it was not identified through this experience, when shifting to distance training encounters it is useful to consider the challenges and limitations that may be faced by the learners, instructors, and involving aspects related to professional competence, professionalism, and nonverbal communication skills. Future studies to use the KADTM as a methodology can examine: (a) the impact of distance training on the learners' affective domainincluding contextual challenges and psychological, social, and cultural barriers.

Limitations: Distance-training programs identified some limitations to be considered, regarding the use of body language andnon-verbal skills. Technicallimitations were also observed with regards to internet-connection speed and reliability. Quality indicators of synchronous and asynchronous online environment efficiency were issues that need to be addressed. Teaching effectiveness and performance quality indicators were two categories were also emerged. Computer anxiety was reported by some students. Furthermore, the accessibility to a stable internet connection can be a limiting factor.

Conflict of Interest: None to declare.

Financial Disclosure: There is no financial disclosure.

\section{References}

1. Field DE. Moving from novice to expert-the value of learning in clinical practice: a literature review. Nurse education today. 2004 Oct 1;24(7):560-5.

2. Farhadi B. "The Sky's the Limit": On the Impossible Promise of E-learning in the Toronto District School Board (Doctoral dissertation).

3. Petrucci C, La Cerra C, Caponnetto V, Franconi I, Gaxhja E, Rubbi I, Lancia L. Literature-based analysis of the potentials and the limitations of using simulation in nursing education. InInternational Conference in Methodologies and intelligent Systems for Techhnology Enhanced Learning 2017 Jun 21 (pp. 57-64). Springer, Cham.

4. Cheng A, Morse KJ, Rudolph J, Arab AA, Runnacles J, Eppich W. Learner-centered debriefing for health care simulation education: lessons for faculty development. Simulation in Healthcare. 2016 Feb 1;11(1):32-40. 
5. Murphy MP. COVID-19 and emergency eLearning: Consequences of the securitization of higher education for post-pandemic pedagogy. Contemporary Security Policy. 2020 May 1:1-4.

6. Zhao J, Xiao H, Li Y, Wen D, Xu P, Fu Y, Piao J, Liu J, Cao D, Zhong Z, Zhao G. Experience of Massive Distance Online Education for Medical Colleges and Universities in China to Counter the COVID-19 Pandemic.

7. Oh PJ, Jeon KD, Koh MS. The effects of simulationbased learning using standardized patients in nursing students: A meta-analysis. Nurse education today. 2015 May 1;35(5): e6-15.

8. Cascella M, Rajnik M, Cuomo A, Dulebohn SC, Di Napoli R. Features, evaluation and treatment coronavirus (COVID-19). InStatpearls [internet] 2020 Mar 8. StatPearls Publishing.

9. Luhanga FL. The traditional-faculty supervised teaching model: Nursing faculty and clinical instructors' perspectives. Journal of Nursing Education and Practice. 2018;8(6):124-37.

10. Barak M, Hussein-Farraj R, Dori YJ. On-campus or online: examining self-regulation and cognitive transfer skills in different learning settings. International Journal of Educational Technology in Higher Education. 2016 Dec;13(1):1-8.

11. Kidd PS, Parshall MB. Getting the focus and the group: enhancing analytical rigor in focus group research. Qualitative health research. 2000 May;10(3):293-308. 